\title{
Experimental research regarding carbon fiberl epoxy material manufactured by autoclave process
}

\author{
Paul Bere ${ }^{1, *}$, Emilia Sabău ${ }^{1}$, Cristian Dudescu ${ }^{2}$, Calin Neamtu ${ }^{3}$, and Marius Fărtan ${ }^{4}$ \\ ${ }^{1}$ Technical University of Cluj-Napoca, Department of Manufacturing Engineering, 103-105 Muncii \\ Blvd., 400641 Cluj-Napoca, Romania \\ ${ }^{2}$ Technical University of Cluj-Napoca, Department of Mechanical Engineering, 103-105 Muncii \\ Blvd., 400641 Cluj-Napoca, Romania \\ ${ }^{3}$ Technical University of Cluj-Napoca, Department of Design Engineering and Robotics, 103-105 \\ Muncii Blvd., 400641 Cluj-Napoca, Romania \\ ${ }^{4}$ S.C. Remarul 16 Februarie S.A., 4 Tudor Vladimirescu Street, 400225 Cluj-Napoca, Romania
}

\begin{abstract}
The fiber reinforced polymers (FRP) represent a group of materials with a very impressive development in the last time. There are used in different applications from aerospace to sports or medicine. Carbon fiber reinforced polymer (CFRP) has special properties and tend to replace traditional materials like steel, aluminum alloys or wood. Different procedures were developed to manufacture the CFRP. Autoclave processing can be considered the most important way to obtain the best mechanical properties of this kind of material. In this paper it is presented the autoclave manufacturing process to obtain the CFRP plates. The autoclave polymerization process steps are indicated for the CFRP made of Twill textile prepreg material. The stacking sequence of the layers is [0/90]. To determine the mechanical properties of the material tensile test on standardized specimens was employed. The obtained mechanical material's properties are comparable with steel but its density was reduced 5.5 times.
\end{abstract}

\section{Introduction}

The composite materials today are applicable in all the industries and the benefits of these bring many advantages for the areas in which they are applied. Good mechanical properties, low density, corrosion resistance, possibility to apply the fibers on the requested direction, chemical resistance, easy manufacturing of complex parts, are just a few of these advantages. Multitude of possibilities to design the composite material implies the necessity to determine their mechanical properties in each case.

In [1] the authors present the mechanical determination of composite CFRP plates using UD and different woven fabrics (Plain, Twill) with $200 \mathrm{~g} / \mathrm{m}^{2}$ for reinforced materials. The wet technology and vacuum bag processing were employed. They use a normal curing procedure in the oven at $80^{\circ} \mathrm{C}$ for 8 hours. A mathematical model of fracture applicable to a biaxial reinforced composite material was presented in [2]. In the experimental research

\footnotetext{
* Corresponding author: bere paul@yahoo.com
} 
section, the authors presented the mechanical results for CFRP Plain tissue by $200 \mathrm{~g} / \mathrm{m}^{2}$ by the same technology mentioned above.

CFRP structure for electric vehicle, using carbon twill woven fabric composite was described in [3]. A multiscale approach was proposed to construct the three-dimensional microstructure and to predict the material elastic model. The authors used some mechanical properties from the technical literature. In [4] the author realizes a review of using composites in modern aircraft construction, especially (CFRP). According to the authors fibre reinforced polymers, especially (CFRP), can and will in the future contribute to more than $50 \%$ of the structural mass of an aircraft. The conventional materials, combination between conventional and composite, and composites are presented in different applications of aircraft constructions. Specific manufacturing technologies for different parts are presented and the influences of the stacking sequence on the mechanical properties of the parts are indicated.

Based on numerical analysis of mechanical properties of CFRP an isogrid cylinder was designed and tested in [5-6]. Numerical analyses of the materials properties are used in designing different applications and studies [7-11].

In the finite element (FE) analyses and designing process the mechanical properties of materials are very important variables. In the case of composite materials this can be difficult to know because their properties are very different the positioning and the curing procedure can influence these parameters. With an anisotropic material behavior determination of composite constants supposed to determine the mechanical properties for individual layers of composite. At the end, a homogenization of the material's layer can be done. The global homogenization coefficients of materials are used in FE numerical analyses to indicate the behavior of the structure. The material's properties can be determined experimentally by subjecting the samples of this material to different mechanical tests. This paper presented the manufacturing method for obtaining CFRP materials. In order to obtain the best mechanical properties, the autoclave curing procedure was applied. There was used the prepreg materials by $240 \mathrm{~g} / \mathrm{m}^{2}$ and Twill fabric type. The epoxy matrix was used. The stacking sequence was [0/90] and four plies were applied. The elastic constants of this material were determined using tensile tests.

\section{Materials and methods}

\subsection{Materials}

To obtain the CFRP plates a GG245T-DT806W-42 prepreg produced by DeltaPreg, Italy was used. The prepreg materials contain carbon fibers twill type with $245 \mathrm{~g} / \mathrm{m}^{2}$, (Tenax HTA-3k), like reinforced material, and epoxy resin, type DT806W as matrix.

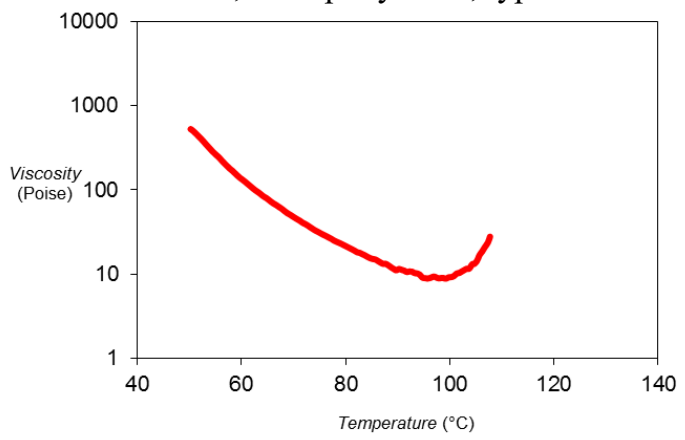

Fig. 1. Viscosity profile of DT806W resin in constant heating rate $2^{\circ} \mathrm{C} / \mathrm{min}[12]$ 
The fraction ratio of resin is $42 \%$. These types of epoxy matrices are in the low to medium viscosity range and offers higher tack, mainly for solvent impregnated fabric prepregs. The Out Life of prepreg is 21 days at $21^{\circ} \mathrm{C}$ and Shelf Life 12 months at $-18^{\circ} \mathrm{C}$. For this reason, the material is deposited in the freezer at $-18^{\circ} \mathrm{C}$. A very important thing is the behavior of resin exposed to temperature. The viscosity profile of resin is indicated in Fig. 1.

The diagram indicates a very low viscosity of the resin around $100^{\circ} \mathrm{C}$. This indicates the interval where the pressure must be at maximum level. During this time the resin can migrate in the carbon and cover all the textile material. The stacking sequence of the layers were $[0 / 90]_{4}$.

\subsection{Manufacturing method}

The main objective of this study is to obtain the best mechanical properties of these materials, using the previous stacking sequence of the layers. For this, the authors was used the autoclave curing process.

To obtain the CFRP plates a steel metal plate mold was used. The active surface of the mold was polished. To prevent the bonding of the composite to the mold surface a type LOCTITE®FREKOTE700-NC TM release agent was applied. The agent layers were applied 10 times. Between layers applications, 20 minute were kept, so the release agent could dry.

The CFRP prepreg was removed from the freezer and kept at $20^{\circ} \mathrm{C}$ during the 6 hours.

The prepreg were cut after the mold dimensions. The layers were applied on the surface mold layer by layer. After the first layer was applied, this was pressured by a vacuum pressure at $-0,9$ bars for 30 minutes. Procedures were done in a vacuum bag.

The next layers were applied by hand layup. Particular attention was payed to conform the prepreg texture to the geometry of the released mold when laminating. The warp and the weft must be at the initial angles and kept at [0/90] for all the layers.

A non-perforated release film was used to cover the CFRP laminate. The mold edges were sealed with tape. This will prevent any leakage of resin from the composite plate that could come into direct contact with the breather and vacuum bag during the curing process.

The mold and composite were covered by a breather. The breather covers the entire mold plate and reaches the vacuum valve. All the composite system was introduced in a vacuum bag, sealed at the border, and a vacuum valve was applied.

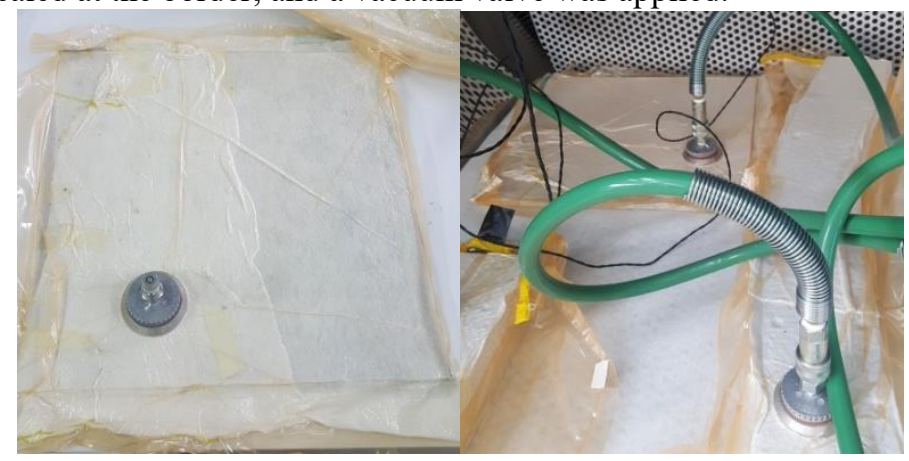

Fig. 2. The mold and composite subjected to vacuum pressure

A vacuum pressure was applied at $-0,9$ bars for 30 minutes. In this time, the vacuum bag was checked to prevent its damage. After this, the autoclave curing cycle was done. The mold subjected by a vacuum pressure was introduced in autoclave connected at the autoclave vacuum system. Autoclave cycle steps are:

1. Heat the mold at $60^{\circ} \mathrm{C}$ for $30 \mathrm{~min}$. 
2. Heat the mold at $2^{\circ} \mathrm{C} / \mathrm{min}$. ramp rate to $120^{\circ} \mathrm{C}$ for $60 \mathrm{~min}$.

3. Dwell at $120^{\circ} \mathrm{C}$ for $120 \mathrm{~min}$.

4. Cool the part at $2^{\circ} \mathrm{C} / \mathrm{min}$ for $60 \mathrm{~min}$.

After the polymerization time the plastic vacuum bag and the auxiliary materials were rejected and the composite plates were release form the mold.

\subsection{Samples preparation}

To determine the mechanical properties of the material, 5 sets of samples from CFRP were cut by $0^{\circ}-90^{\circ}$ and $45^{\circ}$ from the same plate. The tensile stress tests were performed. The cutting direction of the samples is indicated in Fig. 3.

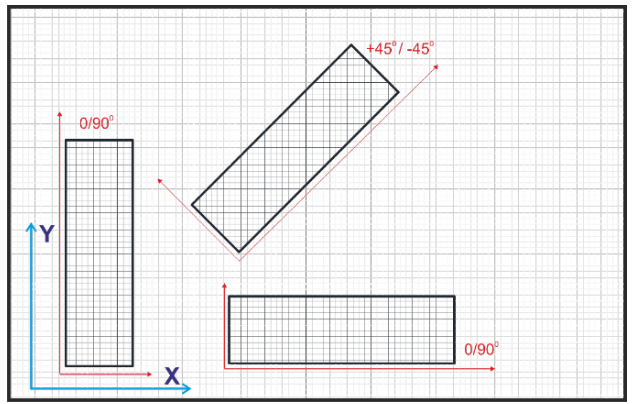

Fig. 3. Samples cutting position

The samples were cut (Fig. 4) according to ASTM D3039M and ASTM D 3518/D 3518M standards [13-14].

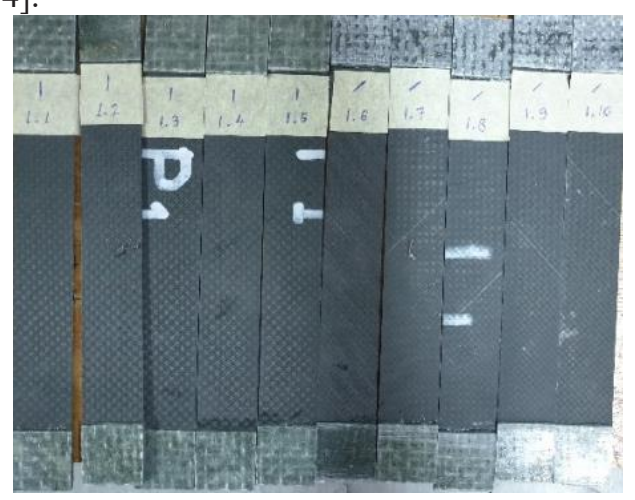

Fig. 4. CFRP samples for tensile stress test

The samples were tested using an INSTRON 8810 servo-hydraulic test frame $(100 \mathrm{kN}$ maximum force) and at a transverse speed of $2 \mathrm{~mm} / \mathrm{min}$. Determination of tensile strain was based on the transverse displacement. To protect the ends of the samples fiber glass tabs were assembled by epoxy structural bond type Scotch-Weld ${ }^{\mathrm{TM}}$, DP9323 A-B, from 3M $\mathrm{M}^{\mathrm{TM}}$.

\section{Results and discussions}

The obtained CFRP plates were analyzed to observe any defects or porosity on surface. The material was compact and no porosity was observed. The density of the obtained CFRP was $1410 \mathrm{~kg} / \mathrm{m}^{3}$. 
Table 1 presents the obtained values of the mechanical properties of CFRP. These results represent the mean values of the subjected samples.

Table 1. The mean value of mechanical properties by CFRP obtained by tensile stress test

\begin{tabular}{|c|c|c|c|c|c|c|c|}
\hline Samples & $\begin{array}{c}\text { Fiber } \\
\text { orientation }\end{array}$ & $\begin{array}{c}\text { Load at } \\
\text { Break } \\
(\mathrm{N})\end{array}$ & $\begin{array}{c}\text { Extension } \\
\text { at Break } \\
(\mathrm{mm})\end{array}$ & $\begin{array}{c}\text { Tensile } \\
\text { strain at } \\
\text { Break } \\
(\mathrm{mm} / \mathrm{mm})\end{array}$ & $\begin{array}{c}\text { Tensile } \\
\text { stress at } \\
\text { Break } \\
(\mathrm{MPa})\end{array}$ & $\begin{array}{c}\text { Tensile } \\
\text { stress at } \\
\text { Tensile } \\
\text { Strength }\end{array}$ & $\begin{array}{c}\text { Chord Modulus } \\
(0.0005 \mathrm{~mm} / \mathrm{mm}- \\
0.0025 \mathrm{~mm} / \mathrm{mm}) \\
(\mathrm{MPa})\end{array}$ \\
\hline $1.0-1.5$ & $0 / 90^{\circ}$ & 13956 & 2.06 & 0.01318 & 634.4 & 0.18 & 48805 \\
\hline $1.5-1.9$ & $\pm 45^{\circ}$ & 4284 & 11.39 & 0.07513 & 194.7 & 141.52 & 15349 \\
\hline
\end{tabular}

The tensile tests indicate a different behavior of the tested samples of CFRP (Fig. 5). The samples with orientation $0 / 90^{\circ}$ have a brittle behavior with a quasi-linear strain-stress relation. For these samples the maximum tensile stress indicates a high value, around 635 $\mathrm{MPa}$. This is comparable with steel in the case that the CFRP density is 5.5 times lower. It must be mentioned that in this case half of the threads are positioned at 0 degrees and half are at 90 degrees. The results are influenced and we can say that only half of the monofilaments are withstanding to tensile force.

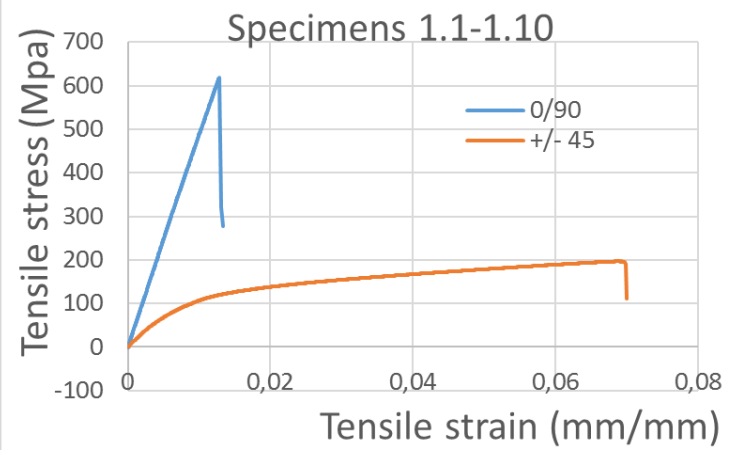

Fig. 5. Tensile stress/tensile strain diagram

For the samples cut at $45^{\circ}$ (Fig. 4) their behavior indicates amore ductile behavior with a higher elongation. This can be accounted considering the distribution of the threads. In the tensile case the monofilaments are not in same direction with the tensile force and the behavior can be attributed to the polymer matrix. This is a specific behavior of ductile material. In this case, the fiber distribution influenced the maximum tensile stress of CFRP. For these samples the mean value is $194 \mathrm{MPa}$ which is quite low. Chord modulus determined based on transverse position is not enough precise being just approximate values. For precise modulus determination strain gauges are recommended to be applied. A brittle fracture can be observed in both cases at the failure time the samples were broken in a couple of pieces and material structure was damaged in.

During the tensile tests the load application is accompanied by sound emission. This indicates that the monofilaments are broken during load application. Sound emission changes from low to high frequencies as the stress increases.

\section{Conclusions}

The mechanical properties of the materials are very important in the design and dimensioning of composite parts. The FE analyses need the input parameters of the materials to estimate their mechanical behavior. In literature or in the software programs we find the generic materials, such as fiber glass or carbon fiber. There is no information about the stacking 
sequence of the layers, weight fraction ratio of the resin or material type. All these have a very important contribution for estimating correctly the material behavior in a simulation. The homogenization of composite layers to determine the material's properties is a complex software solution and not all the time we find all the materials constants in the library. It's complicated to determine the correct material parameters is if we use a numerical analysis. For this the real (measured) parameters of this CFRP [0/90]4 material was determined, in condition of autoclave curing process.

The tensile stress of the obtained material indicates a high value, comparable with steel, but the density of CFRP material decreased by 5.5 times. The autoclave curing of laminate brings a lot of advantages which increase the material properties. The constant pressure applied during the polymerization time realizes a compact structure and keeps the initial architecture of the layers.

Each of the CFRP types has individual material constants. These are dependent on the type of material used, fraction ratio, layer stacking sequence, manufacturing technology and curing procedure. The determination of the mechanical properties for CFRP with specific stacking sequence can validate the FE analyzed and it contributes to the data base of specific material properties. For part with complex surfaces it's very important to use a balanced composite structure where the reinforced materials are applied under different angles. A complex light structure with the similar mechanical properties for different directions was obtained. This can provide mechanical resistance to complex requirements.

Acknowledgements: This work was supported by the project "Advanced technologies for intelligent urban electric vehicles"- URBIVEL - Contract no.11/01.09.2016, project co-founded from the European Regional Development Fund, through the Competitiveness Operational Program 2014-2020.

\section{References}

1. Bere, P., Krolczyk, J.B EEMS Conf., 19, , (2017)

2. Bere P., Berce P., Nemeş O., Composites Part B: Engineering, 43 2237-2243, (2012)

3. Q Liu, Y Lin, Z Zong, G Sun, Q Li, Compos Struct, 97, 231-238, (2013)

4. C Soutis, Progress in aerospace sciences, 41, Issue 2, 143-151, (2005)

5. L. Sorrentinoa, M. Marchettib, C. Bellinia, A. Delfinib, M. Albanob, Compos Struct, 143, Issue 20, 189-201, (2016)

6. G. Totaro, Compos Struct, 129, 101-110, (2015)

7. Bere, P., Popescu, A., Dudescu, C., Hancu, L.- IManE\&E MATEC Web of Conferences, 112,04006, (2017)

8. D.W. Radford, J Compos Tech Res, 15, 290-296, (1993)

9. Dziedzic, K., Zubrzycka-Wrobel, J., Jozwik, J., Barszcz, M., Siwak, P., and Chalas, R., Adv. in Sci. and Tech. Research, 10,(32), 144-149, (2016)

10. Av. Miron, N. Bâlc, A. Popan, C. Borzan, P. Bere, AJME, 11, 2 , (2013)

11. G.M. Krolczyk, P. Nieslony, Krolczyk J.B., Samardzic I., Legutko S., Hloch S., Barrans S., R.W. Maruda, J. Measurement, 70, 203-213 (2015)

12. DT806 Resins - Technical Data Sheet, Delta Tech, www.delta-tech.it1, (2014)

13. ASTM D3039/D 3039M-00,

14. ASTM D 3518/D 3518M - 94, 